Published by the University of KwaZulu-Natal https://journals.ukzn.ac.za/index.php/JICBE

(C) Creative Commons With Attribution (CC-BY)

Journal of Inclusive cities and Built environment. Vol. 1 Issue 2

How to cite: Muringa, T.P. 2021. Challenges and survival strategies of vulnerable groups under Covid-19 induced lockdown: The case of Durban waste pickers. Journal of Inclusive cities and Built environment. Vol. 1 Issue 2, Pg 79-88.

\title{
CHALLENGES AND SURVIVAL STRATEGIES OF VULNERABLE GROUPS UNDER COVID-19 INDUCED LOCKDOWN: THE CASE OF DURBAN WASTE PICKERS
}

\section{By Muringa T. P.}

\begin{abstract}
Evidence suggest that waste pickers are one of the most vulnerable groups during the national lockdown period. Despite the notion that waste pickers are amongst the economically excluded groups in urban South Africa, little is known about their lockdown experience. This study explores the survival strategies of waste pickers in Durban during the COVID-19 induced level 5 lockdown. It employs a case study to illuminate the challenges and various survival strategies adopted by the waste pickers in response to harsh living conditions imposed by the lockdown measures. Two empirical questions are asked in this study- what are the challenges faced by the waste pickers? and what were the surviving strategies employed by waste pickers? Data for this study were collected using semi-structured interviews with pickers. Using a convenience sampling technique, waste pickers $(n=15)$ from the South Beach area were interviewed. The study revealed that the pickers lost income and their assets. As a means of survival, the pickers resorted to drugs, crime, and moved to shelters.
\end{abstract}

KEY WORDS Waste pickers, social and economic inclusion, Durban, National Lockdown

T. P. Muringa $(\mathrm{PhD})$

M\&G Research Consultancy 171 Steve Biko Rd, Musgrave, Durban

E-mail: muringat@mgresearch.co.za 


\section{INTRODUCTION}

Old and recent evidence suggests that waste pickers contribute massively to the functioning of cities. Waste pickers are frequently labelled as the "invisible heroes" that facilitate solid waste management in most South African cities. More so, waste pickers contribute immensely to the movement and management of the local environment and solid waste recycling (Scheinberg and Savain 2015). Dias (2016: 377) argues that waste pickers are a crucial part of the city's solid waste system, the economy, environment, and the quality of the cities public space. They create value for their cities. Similarly, Blaauw, Pretorius and Schenck (2019: 129) argue that most local authorities draw immense benefits from the waste pickers and informal sector activity without paying them wages or any form of a stipend. Waste pickers contribute to increasing the lifespan of landfills by lowering the quantities of waste to be disposed of and are key economic actors in providing inputs to the recycling market with material that would otherwise be dumped (Dias (2016: 376). Further, Women in Informal Employment Globalising and Organising, WIEGO (2021: 1) established that waste pickers are the essential protectors of the environment. They facilitate recycling used material and ensure that it goes for processing by global recycling industries.

The voices and concerns of the vulnerable groups, waste pickers, in particular, have often been subdued in times of emergencies. It is estimated that there are more than 1 million waste pickers globally (Dos Santos, Zolnikov, Ribas, Casabona, Monteiro, Martins, França, de Araújo and Cruvinel 2020). Most of them are found in the global south and under-developed countries. Waste pickers are informal workers whose livelihood and income are dependent on sorting and selling reusable or recycled material that has been discarded by society. South Africa has more than 60000 waste pickers who collect approximate 80 to 90 per cent of used recyclable waste annually (Maleka and DeWet, 2020: 1). Over the years, waste pickers have pursued various strategies in the struggle for inclusivity. These include mass mobilisation, the forging of strategic alliances at both local and national level. The approaches were aimed at influencing integrative policy and legislation to gain recognition and be integrated into the formal sector of the economy. The organisation has taken a form of a membership-based organisation like associations, unions, and community-based microenterprises. However, despite increased efforts to organise or contribute to the local and national economy, waste pickers contribution to the economy and environment are mostly disregarded and undervalued by local authorities. To that end, therefore, they remain excluded from the formal economy of the cities. Moreover, the waste pickers in South Africa receive less recognition in social standing, wages, and protection (Carenbauer, 2021). Blaauw, Pretorius and Schenck (2019: 129-132) argue that waste pickers are repeatedly referred to as the vulnerable, understood through the prism of economics, health, and sustainability.

Because the waste pickers remain largely informal, the advent of COVID-19 induced lockdown disrupted their livelihood and economic system (Rob, 2020). The social distancing regulations that the government announced affected their way of doing work. Additionally, shops and industry closure meant reducing waste material and thus less work and reduced income. Moreover, the limited movement induced by national lockdowns prompts other industries to dispose of their waste rather than recycling (Carenbauer, 2021). Taken together, the disruption in the market poses a considerable threat to the waste pickers who depended on waste recycling for their income. argued that these disruptions pose a larger threat to waste pickers due to the informal nature of their work as many are without social and economic protections (Carenbauer 2021; WIEGO 2021). Thus, the status of the waste pickers as the vulnerable only continues to worsen.
Recently, researchers have shown an increased interest in the challenges and survival strategies of waste pickers. For instance, Carenbauer (2021) explored the challenges waste pickers encounter in relation to COVID-19 in the United States. His findings concluded that waste pickers are vulnerable, and they are often subjected to discrimination and unsafe working conditions during the pandemic. Similarly, Schenck, Blaauw, Viljoen, Swart (2019: 2059) examined the potential health risks faced by waste pickers on landfills in South Africa and established that waste pickers expose themselves to immeasurable health risks because they lack safety protective equipment in the form of clothes, cloves safety shoes and sanitation. Finally, in another study, Kaza (2020) illustrates how the COVID-19 pandemic disruptions posed a grave threat to waste pickers because of the informal nature of their work, as most of them do not have any form of socio-economic protections.

Despite the growing body of knowledge on waste pickers, there is still no consolidated body of research that examines the challenges and survival strategies of waste pickers in South Africa. Currently, attention is being given to means and possible ways of integrating waste pickers into the formal waste management system in South Africa (Coletto and Bisschop, 2017; Schenck et al. 2019; Schenck and Blaauw, 2011). Furthermore, previous research on waste pickers in South Africa also tended to focus on the health risk associated with the work of waste-pickers (Cruvinel, Marques, Cardoso, Novaes, Araújo, Angulo-Tuesta, Escalda, Galato, Brito, and da Silva, 2019; Dalasile and Reddy, 2017; Makhubele, Ravhuhali, Kuonza, Mathee, Kgalamono, Made, Tlotleng, Kootbodien, Ntlebi, Wilson and Naicker, 2019; Schenck et al., 2020) Surprisingly, the challenges and survival strategies of waste pickers have not been closely examined particularly, in the context of the COVID-19 induced level 5 lockdown. Consequently, little is known about the encounters of Durban waste pickers, and it is not clear what survival mechanism they resorted to overcome the hardships 
imposed by the lockdown. It is this lacuna in the literature that prompted this study.

The paper aims to contribute comprehensively to the body of research on waste pickers by examining Durban waste pickers' challenges and surviving strategies in the context of the COVID-19 induced lockdown. Two empirical questions are- (i) what were the challenges faced by the waste pickers, and (ii) what were the surviving strategies employed by waste pickers during the period of hard lockdown?

The paper has three different sections that are devoted to findings. Section II considers the literature on waste pickers in South Africa. Section III focuses on the theoretical framework. Finally, sections IV discusses the findings. The paper concludes by arguing that challenges faced by Durban waste pickers due to the lockdown can be lessened by a concerted, collaborative effort on the part of the waste pickers association, other stakeholders and the local authorities.

\section{2. 'ALERT LEVEL 5' LOCKDOWN: THE SOUTH AFRICAN CONTEXT}

The emergence of the COVID-19 virus that was first identified in China sparked diverse responses from government around the world. In many countries, the fear of the spread of the virus and the unprecedented rise in mortality cases made governance to adopt harsher rules such as national lockdown to restrict movement and social contact for humans. Like all other countries, on the 26 March 2020, South Africa was moved to 'Alert Level 5' of the national lockdown. According to the president of South Africa, Cyril Ramaphosa, 'Alert Level 5' indicates a high COVID-19 spread with a low health system readiness. To that end, the 'Alert Level 5'introduced drastic measures that were aimed at containing the spread of the virus and save lives. Under this level, all business activity was closed except for essential services (clinics, grocery shops, energy industry)

\section{CHALLENGES OF WASTE PICKERS IN SOUTH AFRICA}

Several attempts have been made to investigate the challenges faced by waste pickers. However, such investigations are unsatisfactory in that they pay considerable focus on the heathy risk associated with the trade of waste picking. A consensus among scholars is that the waste pickers, while sorting and collecting the waste, they are exposed to occupational risk and hazards, including cuts from sharp objects and medical waste. These could be contaminated with infection diseases (Dos Santos, Zolnikov, Ribas, Casabona, Monteiro, Martins, França, de Araújo and Cruvinel, 2020: 122-123). Dos Santos et al. (2020: 122-123) found that "there were 755 samples collected for syphilis, 791 for HIV, 866 for hepatitis $B$, and 859 for hepatitis C. Of these samples, $28(3.70 \%)$ waste pickers had reagent serology for syphilis, $6(0.75 \%)$ for HIV; $6(0.69 \%)$ for acute hepatitis B and $1(0.11 \%)$ for hepatitis C." In another study, Mdleleni, Wilson, Ntlebi, Made, Kootbodien, Tlotleng, Makhubele and Naicker (2020: 1) found a prevalence of substance and drug use hostile working condition among waste pickers in South Africa. Made, Nonterah, Tlotleng, Ntlebi, and Naicker (2021: 2-3) established that waste pickers in South Africa are at risk of fatal cardiovascular disease. Their findings revealed that cardiovascular disease was more prominent among waste pickers obese and hypertension (Made et al., 2021: 2-3). Similarly, Schenck et al. (2019: 2059) examined the potential health risks faced by waste pickers on landfills in South Africa. They established that waste pickers expose themselves to immeasurable health risks because they lack safety protective equipment like clothes, gloves, safety shoes and sanitation.

\section{THEORETICAL PERSPECTIVES: RESILIENCE THEORY}

This study employs the resilience theory as it sought to investigate the challenges and surviving strategies employed by the Durban waste piker in the context of the COVID-19 induced lockdown. Resilience refers to the ability of an individual or community to bounce back from adversity, misfortune, or frustration (Ledesma, 2014: 1). Luthans (2002: 702) defines resilience as "the developable capacity to rebound or bounce back from adversity, conflict, and failure or even positive events, progress and increased responsibility." Chazovachii (2020: 139-142) argues that resilience must be construed as the dynamic process or a system to adapt successfully to threats and adversities in one's life. The resilience theory has its roots in the psychology work of Norman Garmezy, who initiated the Project Competence Longitudinal Study (PCLS) and the Masten, Tellegen from the University of Minnesota. The resilience theory's roots are found in a study that studied the outcome of children who were at high risk for psychopathology (Van Breda, 2018: 1-4). The study results revealed that a subgroup of the children could not develop any psychopathology related disorder and developed good health patterns. Chazovachii (2020: 142) argues that entrepreneurship resilience is "augmented by enhanced networks and formation of a professional network of mentors, accepting that change is part of life, and avoiding seeing crises as insurmountable" (Van Breda, 2018: 12). It is the "capacity of individuals to navigate their way to the psychological, social, cultural, and physical resources that sustain their well-being and their capacity individually and collectively to negotiate for these resources to be provided and experienced in culturally meaningful ways." (Greene, Galambos and Lee, 2004: 456) The degree of entrepreneurial resilience does not only depend on the personality and an individual internal factor. Instead, it relies on "structural and external factors. 
It is adaptive resilience which involves a process of continuous transformation and learning in the aftermath of disruptions."

\section{Figure 1: Resilience Theory}

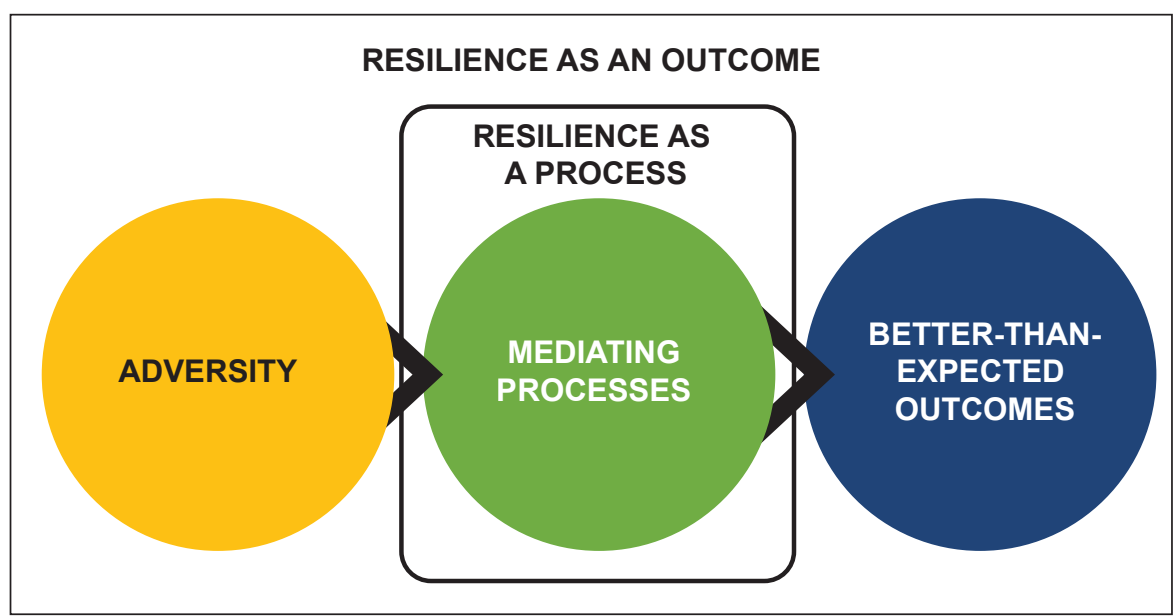

Source: (Van Breda, 2018: 12)

Resilience should be construed as a process that leads to an outcome. The critical attention of resilience theory lies in mediating process. To that end, a person or a social system is said to be "resilient" when they have the potential for good outcomes in the face of harsh conditions. Hedner, Abouzeedan and Klofsten (2011: 79-86) resilience must encompass three elements- adversity, mediating process and positive outcomes as illustrated in Figure 1.1. The concept of resilience is construed as a multifaceted (multilevel) process that the systems absorb to draw out better-than-anticipated results in the face of adversity. In this case, multilevel entails "that resilience processes occur across various fields or levels of the social ecology or person-in-environment, rather than only in the individual." (Korber, Rod and Mcnaughton, 2017: 519) Thus, it implies community and family networks. The community may involve the social environment that encompasses institutions that are either state or non-state entities (Korber et al., 2017: 591). Usually, adversities are of two types- acute or chronic. These are stages of vulnerability contexts that "can be in the form of shocks, stress, trends and seasonality." (Van Brenda, 2018: 543) Therefore, in our context, the adversity is the COVID-19, and it's ensuring lockdown emergency while the mediating process is the waste pickers' capability, resources, and "the transforming structures and processes employed to redress the worsening conditions of vulnerability." (Van Brenda, 2018: 543) The resilience course incorporates mediating. According to Van Breda (2018: 544 ), the mediating process "involves personal intelligence, problem-solving skills, emotional intelligence, motivation to succeed, faith and hope." Nevertheless, it must be noted that a person is made accountable and responsible for dealing with the communal challenges; instead should be addressed by collective structures like the state entities. Chazovachii (2020: 345) argued that "the resilience process does not lie in the individual or the environment but in the way the two transact." The social environment is crucial for sustaining an individual during times of stress. Chazovachii, Chitongo, Tagarirofa and Rukomwe (2020) argue that good social relationships in times of adversities are the restoration of better outcomes as revealed in the affected individual's quality of life society.

Resilience is widely recognised as crucial in achieving the Sustainable Development Goals (SDG) of proper health and good living by the Paris Climate Agreement and the Sendai Framework for Disaster Risk Reduction (DDR). However, resilience has not been proved if it can be enhancing self-resilience in the context of the COVID-19 lockdowns. Therefore, despite its stated weakness, the resilience theory will be applied in this study to argue that the ability of the waste pickers to adapt to the lockdown and
COVID-19 induced lockdown depends on the interaction between the individual and the social environment.

\section{MATERIALS AND METHODS}

The study makes use of the qualitative case study research design. The case study of the Durban waste pickers was employed. A case study design allowed the researcher to explore the complex issues that affected the waste pickers in the lockdown period. An in-depth case study also provides rich data for the profundity analysis and understanding of challenges and livelihood resilience strategies among the Durban waste pickers during the COVID-19 pandemic. While the actual number of waste pickers in Durban is not known, it is estimated that there are over 500 waste pickers that operate in the Durban area. A total of 15 waste pickers participated in the study. A non-probability convenient sampling technique was used to select the 15 wastes pickers around the Durban South Beach area. The South Beach area is central place where most waste pickers that operate in the Durban CBD and town area are found. The waste pickers use the beach for their bathing and recess. They also travel to the South Beach area frequently to collect food parcel that are handed out for free by various charity of organizations. Because of the foregoing reasons, it was convenient for the researcher to interview the waste pickers in the South Beach area.

Data were collected using face to face interviews with the waste pickers. The interview questions allowed the waste pickers to comment on their challenges, vulnerabilities, assets, transformation structures, processes, and survival strategies. The interviews intended to elicit the challenges waste pickers faced because of the COVID-19 lockdown regulations. The interviews also aimed at exposing the resilience strategies of the waste pickers. Data on the challenges and the survival strategies of the waste pickers were thematically analysed. Text from the interviews was analysed and organised under emerging themes. 
The participants were given the consent forms to sign. It was stated and clarified in the consent forms that their participation is voluntary. Further, the participants were informed that they could withdraw their consent at any time of the study without any consequences. This was done to adhere to the ethics code to avoid breaching the participants' rights and avoid harming the participants. In the process of collecting data, all social distance and COVID-19 protocols were observed.

\section{FINDINGS}

\subsection{Diminishing source of income}

The waste pickers were asked in what way the Lockdown level 5 affected them. There was consensus amongst the participants that an enormous effect of the lockdown was the loss of their daily income. The waste pickers revealed that they depend on the wastecollecting job for all their income. Most of the participants did not have any other job experience besides waste piking. When the lockdown was announced, the waste pickers lost little income from the waste-collecting. Moreover, responses from the participants revealed that the waste pickers job depends on the movement and face to face interaction with their clients who are industries. The announcement of social contact and movement restrictions adversely affect the waste picker's ability to collect and sell their goods. Some participants revealed that they were left with stocks that they did not have anywhere to trade because the abrupt announcement of business closure reduced the availability of waste from industry for them to sell.

$\mathrm{KI}$, a waste piker whose only source of income was waste picking, stressed that the COVID-19 induced lockdown ripped him of his source of livelihood. KI said that he does not know any other trade that he can do besides picking waste. Moreover, $\mathrm{KI}$ did not have any form of education to assist him in looking for a better job in the formal sector.
So, for him, the lockdown knocked him hard because he was left with no income. $\mathrm{KI}$ said,

When the Alert Level 5 started, all things were closed. The recycling shops that buy our waste were shut. We were left with no source of income. The lockdown disrupted our source of income. The areas where we collect the waste now were also closed. So basically, we couldn't collect, and we could not sell. At the end of the day, we were left broke.

TS also stressed that she came from very far rural areas in South Coast, where she travelled to go to Durban and pick waste to look after her one child that she left home. TS stresses that the lockdown affected her income in that there was no one else she could get the money to sustain herself and send money back home to help her child. TS said,

.... have never struggled like this. The lockdown affected our monies. We were left with no source of income. We could not move around collecting waste. Even if we found the waste, there were no places to sell it. Everything was closed. The business was down. There was no money to send to my child at home.

Moreover, the lockdown also closed other potential means for waste pickers to get money from the government. TZ, a waste picker, stressed that "I lost my means of income when the lockdown was initiated." But what made the situation worse was for TZ was that he did not have any form of identification that he could use to apply for the government initiated Social Security Grant. For TZ, he could not go and process an identity document during the lockdown because the Home Affairs offices were closed. Thus, TZ's situation was that he missed the opportunity to get a payment after losing income in his trade because he did not have identification.

The findings that the lockdown affected the means and source of income for waste pickers are supported by previous studies. In a study that investigates the adequacy of the resilient mechanisms adopted by selected vulnerable members in Masvingo urban in facilitating selfreliance under COVID-19 induced lockdown conditions, Chazovachii (2021) found that the lockdown affected the informal traders more than the formal sector. For these scholars, the abrupt announcement of social distance policy and close of shops meant that the movement of good in the in/formal sector comes to an end. The waste traders were grounded because their business relied heavily on face-to-face transactions. In a different study, Febrianto (2021: 68) found that "instabilities generated by the COVID-19 pandemic produced enormous diminishing income." Schenck and Blaauw (2011) echo the same sentiments when they argue that waste pickers generate income when people and industry generate waste. Because of social distancing and movement restrictions during the level 5 lockdown, there was a reduced waste generation, and there was no industry operating for the waste pickers to go and sell their goods. Our findings are further supported by Chazovachii (2021), who found that under lockdown, most informal traders were experiencing economic losses due to goods that have remained unsold. In many cases, the informal traders have gone to waste because their market could not absorb their products.

\subsection{Displacement and loss of assets}

When responding to the question of what challenges they encountered during the level 5 lockdown, almost all the interviewees indicated that they had been displaced from their original places where they have been residing for years now. Owing to the lockdown, waste pickers do not have a "permanent" shelter. Often, waste pickers stay in shacks built of plastic and cardboard boxes. The waste pickers revealed that they lost their shacks and assets when the lockdown started. In addition, they indicated that the police were roaming around the streets in Durban, harassing them and making them comply with the 'Alert Level 5' regulations. The harassment by the police and the soldiers who were given the mandate to 
ensure that there is no one in the streets and that the social distance regulations are observed made them abandon their places and search for "safer places" where they are not vulnerable to the attack by the security forces.

For instance, TIT revealed that he did not have a single place to sleep for most of the lockdown. TIT was moved from his comfort zone when the soldiers pounced at him in the middle of the nightbecause of that. TIT spent most of the time moving from place to place, running away from police and soldiers. TIT said he did not have a place he calls home to go and stay when the lockdown was announced. TIT said,

I had no place to stay during level 5. It was tough. The police were running after us, and we never had a single place where we could sleep as we did before the lockdown.

TIT left home five years ago, and his parents are late, and there is no one there at the house he can go to. Even if he goes there, he does not think his relatives will accept him because he was using drugs and previously involved in crime.

The challenge of displacement and loss of assets were also echoed by ZIP, who revealed that under lockdown, most waste pickers were displaced from their "safe places" where they were staying after the police invaded the area and patrolled the sites every day. ZIP, who said he had created a safe and comfortable place for himself to sleep under the bridge with a shack and a mattress, said he lost the shack and other belongings. ZIP said.

When the police showed up one night un-announced, they just pounced on my small shack and destroyed everything, and I ran away, living my place and all my staff that was in the shack. So I lost everything that I had worked for.

Additionally, the issue of loss of assets was also emphasised by DIP, who has worked as a waste picker for almost seven years. DIP has been staying under the bridge in Maydon Wharf for four years, where he accumulated assets like radio, mattress, shack, clothes, and other accessories. DIP lamented the loss of all belongings due to the police raids conducted almost every day in that area. For DIP, the displacement has cost the waste pickers the assets they have worked for. DIP said,

I had lost everything I had worked for when the police raided my place. When I came back to look for the things, I found my previous place empty. My radio and shack are gone. And I was heartbroken. It's not only me. Many of us lost our belongings during the lockdown.

From the above responses, key findings emerged- (i) the waste kippers were displaced, (ii) in the process of displacement, the waste pickers lost most of their assets. Our findings seem to corroborate evidence from previous studies that argue that the displacement and loss of assets is a common challenge encountered by waste pickers in South Africa. Mudavanhu (2020) revealed that waste pickers do not have a permanent place to stay because they always run away from the authorities. For Mudavanhu (2020), waste pickers are commonly known for staying and sleeping in the streets and do seldom have proper houses to sleep or stay. Our findings revealed that at night after they retire from the businesses of the day, the waste pickers sleep outside the shops and under bridges in the outskirts of Durban. These are not safe because they are always at loggerheads with the shop owners and the municipal authorities (Schenck et al., 2021).

Additionally, Schenck and Blaauw (2011) also reported the challenge of displacement in a study conducted in Pretoria. Schenck and Blaauw (2011) found that the daily waste pickers are constantly on the move looking for a proper and safe to sleep. Similarly, waste pickers interviewed in Cape Town expressed the same sentiment when they highlighted that they do not stay at home. They move from one place to the other every night, searching for a safe place to sleep. Loss of assets due to theft was also indicated as one of the challenges that waste pickers encounter across South Africa. McLean (2000) noted that the Durban waste pickers experienced theft problems, lack of accommodation and access to basic facilities. The waste pickers indicated that when they go to collect waste, they would come back and find most of their belongings taken. Mkhize, Dube and Quazi (2014: 44) found that "the lack of shelters exposes waste pickers to harsh weather conditions and makes it difficult for them to operate."

\subsection{Survival strategies during COVID-19 induced lockdown level 5}

The second question that the waste pickers were asked is how they managed to survive during the lockdown. From the responses, three outstanding themes emerged- (i) shelters, (ii) crime, (iii) government grant.

\subsection{Shelters}

Almost half the participants revealed that during the level 5 lockdown, they sought refuge in shelters around the city of Durban. For instance, DZ, who did not have a family and a home to go to, resorted to the church shelter. DZ said he opted for the church shelter because he required food, safety, and a place to sleep. DZ said he was afraid of the crime in the street, so he moved to the shelter. DZ said,

... I looked for a shelter in Durban. I stayed there, and we will get food and blankets to use. But still, things were hard because there was no money there. It was only food, and I did not want to stay there...

DX shared the same sentiments and retorted that he was fortunate to get a shelter to stay with his friends during the lockdown. He expressed that because he could get food, friends and a place to sleep at the shelter. 


\section{Below is DX's response}

...we got stuck, and we lost our income and shacks; we were also displaced. We are so lucky to get a close shelter there that belongs to a church. They welcomed us, and we stayed there. There was food and a place to sleep. That was better because we were stuck. We did not know what to do.

DY, who did not have a family support structure nor friends to go to when the lockdown was announced, express the feeling that he moved to the shelter where he got food and a place to sleep. But he was concerned with the loss of income as he was used to making his own money. Below is DY response.

I moved to the shelter to look for a place to sleep and food. This place was not pleasant. I wish the lockdown ends because there was no means to get money in shelter in the shelter like we did when collecting waste. We made a living from the waste. Now when you are staying in the shelter, you are just there, and everything is closed. The only thing you do is to wake up and eat and sleep. But I must say, staying in the shelter was better than not having a place to say.

From the responses above, two issues emerged- (i) the waste pickers resorted to the shelters for food and sleep as a means for survival, (ii) the shelter was a mediating process in the journey to build resilience for most waste pickers. To illustrate, the shelter served as a survival strategy to avoid hunger and crime. Our findings here seem to be in line with the results from a previous study that argues that waste pickers often look for crowded places and stay in groups to avoid attacks and share food as a means of survival. For instance, Mudavanhu (2020) established that waste pickers utilise social capital as a means of survival. Waste pickers leave in groups. They work in pairs and sometimes share their earnings. Mkhize et al. (2014: 44) found that the waste pickers helped each other with things such as loans, food, and shelter to sleep and shared what they had collected. In a study of waste pickers conducted in Durban, Schenck and Blaauw (2011) found that $36 \%$ of the waste pickers depend on food from the church shelters.

\subsection{Crime}

When the participants were asked about the survival strategies, some commented that they resorted to crime and drug use for survival. Generally, crime is said to be high among waste pickers. The participants identified crimes like pocket piking, drugs, robbery, and burglary as the form of crime they resorted to. Participants indicated that due to the loss of the only income stream, some have resorted to crime to survive the lockdown. Many waste pickers expressed concern that they and their friends were housebreaking and robbing people in the shopping malls and streets. The same participants who were engaging in crime also revealed that as a form of resilience against the lockdown induced hardships, they were using drugs like marijuana and hunga ${ }^{1}$ to cope with stress.

CA, who did not have any other means of making an income during the lockdown, stressed that his friends were now involved in house break-ins and burglary in some parts of Durban. CA said he was invited a couple of time to be involved in crime. Below is CA's response:

I know a group of friends who invited me to go and steal there in Reservoir Hills, saying that the Indians who stay there have a lot of money in their houses.

I have always been using drugs to make myself feel good. But, you know lockdown is stressing a lot. You can't go through a day sober; you die.

Similarly, CB, a former inmate, expressed that the living conditions under lockdown were so severe that they forced him to relapse into crime. He said that his income was badly affected and that crime was the only possible means to make money to assist him. CB said.

\footnotetext{
It's a common street intoxicating drug used in South Africa. It is a mixture of various "unknown" drugs.
}

.......my friends have now gone back to crime. When I came out of prison, I told myself that I would not commit a crime again. That is why I was now picking the waste to sell so that I can have an income. But look now, because of the lockdown, our only hustle is closed, and the only thing that my friends and I could do is go back to their old ways.

The hustle is dangerous and demanding. It would be best if you were high...... smoking helps me a lot like a waste piker.

The sentiments of recidivism and relapse into crime were also shared by $C E$, who said he was involved in crime before he ventured into waste piking. For $\mathrm{CE}$, crime was a sole survival strategy available to him during the lockdown because no other trade they knew. CE expressed the feeling that he could not blame himself for the crime because he was trying to survive.

Sometimes I was involved in stealing here and there. But I did not want to do it. But the lockdown forced me to do so because we could not pick waste anymore because of the lockdown. The only thing that could give us some money was to take something from people. And I do not blame myself for that because there was nothing I could do to survive the lockdown.

The issue of drug use was mentioned by $B E$, who revealed that he went back to his home family to look for survival. Unfortunately, when he got to his location, he got involved in drug dealing. Below is BE's response.

When the country was closed, I went to a boss in the location who deals with drugs. I told him that I am struggling with my brother because there is no waste picking anymore. He gave me a job. I started selling his drugs (tsangu ${ }^{2}$ ) in the neighbourhood.

Furthermore, BID responded by saying that the lockdown brought much suffering to him, and the only alternative he had was to engage himself in crime so that he can earn a living. He said,

2 A Zulu name for marijuana 
... I have struggled so much with this lockdown, and I do not know how I survived. I was forced to resort to stealing from people now, something that I do not want to do- so that I can stay in this lockdown. The stress of lockdown requires someone to be high. So I was smoking hunga. It took me through

Moreover, the sentiment that smoking was used as a coping mechanism also featured in BIC's response when he said that he had absolutely nothing to survive on other than smoking. He stressed that he would come twice a day and spent the whole day sleeping.

Put together, the responses above points to two key issues: (i) the waste pickers resorted to crime as a form of survival during the lockdown, (ii) the harsh effect of lockdown forces the ex-convicts to relapse into crime. Overall, our findings suggest that crime is common practice and survival strategy for waste pickers. Our results corroborate with previous studies that revealed that as a survival strategy and coping mechanism, waste pickers augment their income by resorting to crime. For example, in a study conducted in Pretoria, McLean (2000) found that at the point of entry into the trade of waste piking, an individual's first thing to do is to acquire a trolley. This trolley is obtained through theft. In addition, Schenck et al.'s (2019) revealed that residents complained that the waste pickers were involved in stealing cell phones in the local community.

From the data, it also emerged that the waste pickers used drugs as a way coping mechanism. This finding fits well with results reported by Mdleleni et al., who established that $96 \%$ of the waste pickers' resort to drug and substance use as a means to cope with the adverse working conditions and low income. This study, though not conducted during COVID-19, is instructive and generative. They allow us to understand how substance use is usually a resort when the mediating process of resilience (social environment) fails to assist individuals in building resilience. In the event where the interplay between the individual and the mediating process fails to produce better outcomes, drug and substance abuse is often resorted to as a coping mechanism in the face of adversity, as seen by the Durban waste pickers during the lockdown. A study by Mudavanhu (2014) revealed that most waste pickers have alcohol and drug abuse problems. The waste pickers' resort to drugs and alcohol as a coping mechanism to the trade pressures. Furthermore, our findings are also supported by results from Mdleleni (2021) study, which found that drug abuse and problematic drinking among waste pickers in Johannesburg was associated with mental distress and

\subsection{Government grant}

The community and government entities occupy a crucial role in the mediating process of resilience to produce a better outcome. When asked about their survival strategies during the lockdown. A small number of the waste pickers revealed that they received the government Social Security Grant. When the president of South Africa announced the lockdown in March 2020. The government also introduced some COVID-19 relief packages for the vulnerable groups in Social Security Grant. The beneficiaries of the grant included the elders, the unemployed and the disabled. This included the waste pickers.

AIM is a school dropout who went to school but did not complete his matric and reside in Sydenham, Durban. AM said he managed to apply for the government Social Security Grant where he was receiving $\mathrm{R} 350$. He said, with this money, he was able to sustain himself because there was no other means he could look after himself. He said,

I was fortunate to get the Social Grant. It helped me. I know it was little by it made a difference.

ZIP also echoed the same sentiments when he said the government Social Security Grant was really of assistance during the time of lockdown. ZIP said,
When the country was closed, all things stopped for me. I could not collect waste now, and I did not have a source of income. The government came to our rescue.

Similar sentiments were expressed by $A C$, who retorted that he did not have any means of income nor ways to raise income since he did not go to school. AC did not know other trade other than piking waste in Durban. AC expressed gratitude and happiness for receiving the social grant because it made his life a bit easier during the lockdown period. Below is AC's response.

I applied for the grant that the government introduced. Though small, it made a difference to me. I do not even know how I would survive this period until we can go back and collect waste.

Put together, from the above responses; the following conclusions can be made: (i) some waste pickers made use of the government social security service grant to survive the harsh conditions imposed on them by the lockdown measures. (ii) The government initiated social security grants during the COVID-19 lockdown went a long way in reducing the hardship and destitution among the most vulnerable sectors in the society.

\section{OUTCOMES OF THE COVID-19 LOCKDOWN SURVIVAL/RESILIENT STRATEGIES}

\subsection{Financial capital}

Most of them did not manage to access various income and livelihood assets from the interviews with waste pickers. However, some managed to secure financial capital that sustains them from the government social security grant.

\subsection{Social capital}

Moving into shelters during the lockdown should be understood worked as social capital for the waste pickers. It brought integration, connectivity, networks, and some form of the family for the waste pickers whose social contacts 
restrictions disrupted previous links and networks.

Applying the resilience theory by Van Breda (2018), we observed that harsh conditions among the waste pickers were marred by displacements, movement restrictions, loss of assets and loss of income. Among the Durban waste pickers, the surviving strategy and resilience process have been resorting to crime and drug use, moving into shelters and government social security grants. The resilient strategies have brought financial and social capital to manage the effect of the COVID-19 lockdown. The economic and social capital helped reduce extreme destitution and vulnerability, which have exposed them to the social security and health of the waste pickers. In addition, the government social grant brought supplementary income to some waste pickers.

\section{CONCLUSION}

This paper set out to investigate the challenges faced by waste pickers during the level 5 lockdown. It also explored the surviving strategies employed by Durban waste pickers to regain resilience under the lockdown. The study revealed that the waste pickers lost income and their assets during the lockdown. As a means of survival, the waste pickers resorted to drugs, crime, shelters and depended on the government social security grant. Moreover, from this study's discussion, it can be summed up that the resilience theory offers a comprehensive theoretical framework for fathoming resilient livelihood strategies of the waste pickers in the period of COVID-19 induced lockdown. The theory has improved diminuendos related to hardships. Furthermore, it has exposed the enduring nature of the COVID-19 pandemic to the Durban waste pickers. Regarding the mediating process, the theory offers valuable answers that the resilience process does not depend on the individual alone or in the broader social environment. Instead, resilience depends on the integration of the individual and his society and its entities. The individual and the social environment's mutuality helps the waste pickers recuperate a positive livelihood outcome.

\section{ACKNOWLEDGEMENTS}

\subsection{Disclosure statement}

There are no competing interests to disclose.

\subsection{Consent for publication}

All parties involved have given consent for publication.

\subsection{Ethics approval and consent to participate.}

The ethical clearance certificates to carry out this study was obtained from the M\&G Research Consultancy (PTY) Ltd.

\section{ADDITIONAL INFORMATION}

\subsection{Funding}

The study was not funded.

\section{REFERENCES}

Blaauw, D., Pretorius, A. and Schenck, R., 2019. The economics of urban waste picking in Pretoria. African Review of Economics and Finance, 11(2), pp.129-164.

Chazovachii, B., 2020. Understanding Strategies for Resilient Livelihoods by Masvingo Urban's Vulnerable Groups During the Covid-19 Pandemic in Zimbabwe. African Journal of Governance \& Development, 9(1.1), pp.139-159.

Coletto, D. and Bisschop, L., 2017. Waste pickers in the informal economy of the global South: Included or excluded?. International Journal of Sociology and Social Policy, 37 (5/6), pp. 280-294. https://doi.org/10.1108/ IJSSP-01-2016-0006

Cruvinel, V.R.N., Marques, C.P., Cardoso, V., Novaes, M.R.C.G., Araújo, W.N., Angulo-Tuesta, A., Escalda, P.M.F., Galato, D., Brito, P. and da
Silva, E.N., 2019. Health conditions and occupational risks in a novel group: waste pickers in the largest open garbage dump in Latin America. BMC public health, 19(1), pp.1-15.

Dalasile, M. and Reddy, P., 2017. Respiratory health risks and exposure to particulate matter (PM2. 5) among informal waste pickers at a Durban, South Africa landfill site. African Journal for Physical Activity and Health Sciences (AJPHES), 23(1.1), pp.45-58.

Dias, S.M., 2016. Waste pickers and cities. Environment and Urbanisation, 28(2), pp.375-390. doi:10.1177/0956247816657302

Dias, Sonia Maria (2011a), "Statistics on Waste Pickers in Brazil", WIEGO Statistical Brief No 2, Cambridge, MA and Manchester, UK, 3 pages, available at http://wiego.org/sites/wiego.org/files/ publications/files/Dias_WIEGO_SB2. pdf.

Dos Santos, F.S.G., Zolnikov, T.R., Ribas, I.B., Casabona, J., Monteiro, E., Martins, E., França, D., de Araújo, W.N. and Cruvinel, V.R.N., 2020. Syphilis and other sexually transmitted infections among waste pickers in Brasilia, Brazil. Waste Management, 118, pp.122-130.

Duneier, Mitchell (1999), Sidewalk, Farrar, Straus \& Giroux, New York, 400 pages, page 43.

Hedner, T., Abouzeedan. A., and Klofsten, M. (2011). Entrepreneurial Resilience, Annals of Innovation \& Entrepreneurship, 2:1, 79- 86. DOI: 10.3402/aie.v2i1.6002

Kaplan, Rob, 2020. COVID-19 Underscores The Need To Invest In Local Waste Management And Recycling To Combat Ocean Plastic. Forbes, April 3, 2020. https://www. forbes.com/sites/robkaplan/2020/04/03/ covid-19-underscores-th e-need-toinvest-in-local-waste-managementand-recycling-to-combatoceanplastic/\#325766f24bb1.

Korber, S., Rod, B., \& Mcnaughton, S. (2017). "Resilience and Entrepreneurship: A Systematic Literature Review", International Journal of Entrepreneurial Behaviour \& Research, 41: 6, 519-539. 
Made, F., Ntlebi, V., Kootbodien, T., Wilson, K., Tlotleng, N., Mathee, A., Ndaba, M., Kgalamono, S. and Naicker, N., 2020. Illness, Self-Rated Health and Access to Medical Care among Waste Pickers in Landfill Sites in Johannesburg, South Africa. International journal of environmental research and public health, 17(7), p.2252.

Makhubele, M., Ravhuhali, K., Kuonza, L., Mathee, A., Kgalamono, S., Made, F., Tlotleng, N., Kootbodien, T., Ntlebi, V., Wilson, K. and Naicker, N., 2019. Common Mental Health Disorders among Informal Waste Pickers in Johannesburg, South Africa 2018-A Cross-Sectional Study. International journal of environmental research and public health, 16(14), p.2618.

Maleka, T. and DeWet, P. 2020. Helping South Africa's waste pickers face the COVID-19 crisis and beyond. https:// www.unido.org/stories/helping-southafricas-waste-pickers-face-covid-19crisis-and-beyond

Mdleleni, S., Naicker, N., Made, F., Ntlebi, V., Kootbodien, T., Tlotleng, N., Makhubele, M. and Wilson, K., 2021. Risk factors for problematic alcohol use among male waste pickers and caddies in Johannesburg, South Africa: a cross-sectional study. Archives of Environmental \& Occupational Health, pp.1-11.Mkhize, Sibongile \& Dube, Godwin \& Quazi, Tasmi. (2014). Waste pickers in Durban, South Africa.

Mudavanhu, N., 2020. 'An analysis of livelihood of landfill waste pickers in South Africa'. Master's degree, University of the Western Cape. http:// hdl.handle.net/11394/7310

Rosaldo, M., 2018. From disposable people to professional recyclers: Waste pickers' struggle for labour rights in Brazil and Colombia (Doctoral dissertation, $\mathrm{PhD}$ dissertation, University of California, Berkeley).

Scheinberg Anne, Savain Rachel (2015), Valuing Informal Integration: Inclusive Recycling in North Africa and the Middle East, GIZ and SWEEP-Net, Eschborn, 164 pages.
Schenck, C.J., Blaauw, P.F., Viljoen, J.M. and Swart, E.C., 2019. Exploring the potential health risks faced by waste pickers on landfills in South Africa: a socio-ecological perspective. International journal of environmental research and public health, 16(11), p.2059.

Schenck, Catherina J., Blaauw, Phillip, Viljoen, Jacoba M.M., Swart, Elizabeth C., 2019. Exploring the potential health risks faced by waste pickers on landfills in South Africa: a socio-ecological perspective. Int. J. Environ. Res. Public Health 16(11), https://doi.org/10.3390/ ijerph16112059.

Schenck, R. \& Blaauw, P.F. 2011. The Work and Lives of Street Waste Pickers in Pretoria-A Case Study of Recycling in South Africa's Urban Informal Economy. URBAN FORUM, 22:411-43

Schenck, R. and Blaauw, P.F., 2011, December. The work and lives of street waste pickers in Pretoria-a case study of recycling in South Africa's urban informal economy. In Urban Forum (Vol. 22, No. 4, p. 411). Springer Netherlands.

Sharma, H.B., Vanapalli, K.R., Cheela, V.S., Ranjan, V.P., Jaglan, A.K., Dubey, B., Goel, S. and Bhattacharya, J., 2020. Challenges, opportunities, and innovations for effective solid waste management during and post COVID-19 pandemic. Resources, Conservation and Recycling, 162, p.105052.

Sibongile Mkhize, Godwin Dube and Tasmi Quazi (2014) Waste Pickers in Durban, South Africa Waste Pickers in Durban, South Africa. Available at https://www.wiego.org/sites/default/ files/publications/files/Mkhize-IEMSDurban-City-Report-Waste-Pickers.pdf [Accessed 24/04/2021

Tebogo Maleka and Petronella DeWet (2020) Helping South Africa's waste pickers face the COVID-19 crisis and beyond. https://www.unido.org/stories/ helping-south-africas-waste-pickersface-covid-19-crisis-and-beyond Accessed on 23/06/21.

Van Breda, A.D., 2018. A critical review of resilience theory and its relevance for social work. Social Work, 54(1), pp.1-18. 